\title{
Die verhouding tussen die Heidelbergse Kategismus \\ en die Kort Begrip van Faukelius - met besondere verwysing na die teologiese klemverskuiwings in laasgenoemde
}

\author{
GC Velthuysen
}

Pretoria

\begin{abstract}
The relation between the Heidelberg Cateehism and the 'Kort Begrip' of Faukelius - with particular emphasis on the theological shift in the latter

It is indicated in this article that the theological shift from the point of view of the Heidelberg Catechism to that of the Kon Begrip of Faukelius is the result of three things: The fact that the latter was intended to be an abridged version of the former, that it had its own peculiar intention and that it became a vessel for the scholastic trend in orthodox theology. Some attention is also given to the possible influence the prolonged use of the Kort Begrip as official handbook for the Catechism, had on the theological thought and practice of the Nederduitsch Hervormde Kerk van Afrika.
\end{abstract}

\section{INLEIDEND}

Dit is nou al reeds meer as 'n dekade dat die Kort Begrip nie meer deur die Nederduitsch Hervormde Kerk van Afrika as kategesehandboek gebruik word nie. Dit het trouens geen status meer in dié kerk nie. Dit word hoogstens nog waardeer as 'n interessante historiese dokument terwyl daar dalk hier en daar iemand sal wees wat met 'n mate van nostalgie daaraan sal terugdink omdat hy sy katkisasiedae daarmee identifiseer. Alles dui daarop dat dit kort voor lank in die vergetelheid sal verdwyn sodat dit niks meer sal wees nie as 'n voetnoot in die kerkgeskiedenis.

Waarom dan nou nog aandag daaraan gee? En nie net aan sy dárwees nie, maar ook aan sy teologiese inhoud? Beslis nie in 'n poging om dit op een of ander wyse te restoureer nie - dit kan gerus maar in die newels van die geskiedenis weg- 
raak. Aan die ander kant egter ook nie net om dit as 'n interessante en ietwat eienaardige oudheid vir 'n oomblikkie van die rak te haal, te bekyk en terug te plaas nie. Dit is nodig om duidelikheid te verkry oor die teologiese inhoude van die Kort Begrip omdat dit teologiese inhoude is wat nog wyd in die kerk loop - omdat geslagte hervormers hierdeur gevorm is. Die feit dat dit geslagte lank die status van amptelike kategeseboek gehad het, het dit buitengewoon invloedryk gemaak. Dit het nie net vorm gegee aan teologiese inhoude nie, maar selfs ook aan die wyse waarop teologie beoefen is in die sin dat dit 'n bepaalde denkstruktuur onder die kerkvolk gevestig het. Hiermee moet daar steeds rekening gehou word. Verreweg die meeste van die tans nog lewende hervormers het immers hierdie vorming ondergaan.

Dit is uiters sinvol om die Kort Begrip egter nie in isolasie te bekyk nie, maar in verhouding met die Heidelbergse Kategismus. Wanneer dit langs die belydenisskrif geplaas word, tree die eie aard en karakter daarvan die beste aan die lig.

\section{DIE KORT BEGRIP}

Die Heidelbergse Kategismus is in 1562 deur die Heidelbergse sinode goedgekeur en in 1563 vir die eerste keer gedruk. Teen die begin van die sewentiende eeu was dit wyd deur die gereformeerde wêreld in gebruik en is dit vry algemeen as gesaghebbend aanvaar. Ten spyte daarvan dat dit oorspronklik bedoel is as katkisasieboek vir die kinders en onderrig vir die man in die straat, het die oortuiging spoedig hier en daar ontstaan dat dit te uitvoerig en moeilik is vir die eenvoudiges om baas te raak en het die behoefte aan 'n eenvoudiger oorsig oor die Christelike leer ontstaan. Die oortuiging het veral in Middelburg begin leef waar, danksy die werk van die predikante van die stad, waaronder Hermanus Faukelius en Willem Teellinck, baie van die ou Dopers na die Hervormde Kerk oorgegaan het. Met die oog op hulle eerste nagmaalsviering was daar behoefte aan 'n leerboekie wat betreklik vinnig baasgeraak sou kon word.

Daar wás so 'n boekie beskikbaar en in gebruik: Korte ondersoekinge des ghelooves over den ghenen, die haer tot de gemeynte begheven ende des Heeren avondtmaal mit haer houden willen. Dit was 'n vertaling en bewerking deur Micron van 'n Latynse Kategismus, deur á Lasco opgestel en reeds in 1554 ten dienste van die Nederlandse Hervormde Gemeente in Londen uitgegee. Die probleem met hierdie boekie was egter dat sy volgorde heeltemal anders as dié van die Heidelberger was. $\mathrm{Na}$ mate laasgenoemde se gewildheid en gesag toegeneem het, het die onbehaaglikheid met eersgenoemde toegeneem. Uiteindelik het die kerkraad van Middelburg in 1608 aan sy predikante opdrag gegee om 'n nuwe boekie op te stel. 
S6 maak die Kort Begrip der Christelijke religie in 1611 sy verskyning. Dit maak ook baie gou sy merk - tot so 'n mate so dat die Sinode van Dordrecht dit twee maal as 'recommendabel' aandui. Dit verkry nooit werklik kerklike gesag nie, maar dit word sedert 1637 in die kerkboeke opgeneem en ná die psalms by die formuliere geplaas. Sodoende het dit, ten spyte van sy gebrek aan amptelike status en as gevolg van sy toeganklikheid, sy latere invloedryke posisie in die kerk verwerf.

\section{KLEMVERSKUIWINGS BY DIE KORT BEGRIP}

Dat daar klemverskuiwings by die Kort Begrip voorkom wanneer dit met die Kategismus vergelyk word, is met die hande te tas. Hierdie studie sal aantoon hoedat hierdie klemverskuiwings deur drie verskillende sake veroorsaak is.

- In die eerste plek deur die blote feit dat dit 'n verkorte en gekondenseerde weergawe van die Kategismus wil gee. Dit beteken asof vanselfsprekend dat bepaalde sake uit die Kategismus glad nie, of net gedeeltelik, in die Kort Begrip ter sprake kom. Daar sal aangetoon word hoe dit veranderde teologiese klemtone tot gevolg het.

- Ten tweede deurdat die Kort Begrip 'n eie unieke bedoeling gehad het en dus vanaf die eerste oomblik 'n ander gerigtheid as die Kategismus het.

- Derdens deurdat die tydsvérloop van agt en veertig jaar vanaf die eerste verskyning van die Heidelberger tot by die eerste uitgawe van dieKort Begrip nie sonder betekenis was nie. Op teologiese gebied het daar gedurende hierdie halwe eeu in ieder geval betreklik groot verskuiwings plaasgevind en dié het, soos verwag kan word, in die Kort Begrip neerslag gevind.

\section{KLEMVERSKUIWING AS GEVOLG VAN VERKORTING}

Twee kategorieë van verkorting is ter sprake. Aan die een kant is daar die verkorting van uitsprake wat in die Kategismus voorkom, met die klaarblyklike bedoeling om die essensie van wat die Kategismus stel, weer te gee. Daarnaas is daar sprake van 'n drastieser inkorting wat daarop neerkom dat bepaalde sake glad nie ter sprake kom nie. In ons behandeling van die verskynsel, gaan ons aandag gee aan voorbeelde uit die tweede kategorie.

Waarskynlik die opvallendste en bekendste voorbeeld van 'n weglating by die Kort Begrip, is die feit dat die wet nie in die deel oor die dankbaarheid ter sprake 
gebring word nie. Dit is algemeen bekend dat die Kategismus die wet juis dár ter sprake bring as reël van die dankbaarheid, terwyl dit in die Kort Begrip, vir sover as wat dit figureer, funksioneer as kenbron van die sonde. Dit het onvermydelik tot gevolg gehad dat daar by diegene wat deur die Kort Begrip gevorm is, ' $n$ verengde waardering vir die wet ingetree het - 'n verskraling waarvan die gevolge vandag nog in die liturgiese posisie van, en waardering vir, die wet sigbaar word. Dit het onder andere die gevolg dat die etiek aan belangrikheid inboet en dat oormatige klem geplaas word op die onvermoë om die bepalings van die wet na te kom. Dit het op sy beurt die positiewe gevolg van 'n baie sterk beklemtoning van die soteriologie steeds egter met die negatiewe keersy van die onderbeklemtoning van die etiek.

'n Tweede voorbeeld is die Kort Begrip se bykanse verswyging van die kerklike tug. In die Heidelberger word drie uitvoerige antwoorde aan die behandeling van hierdie saak gewy (vraag en antwoord 82-85) terwyl dit by die Kort Begrip eintlik net sydelings ter sprake kom. Terwyl die Kategismus oorgaan tot 'n betreklik uitvoerige behandeling van die sleutelmag, met klemlegging op die feit hoé hierdie mag aangewend moet word om die hemelryk te sluit en oop te sluit en wanneer dit moet gebeur, volstaan die Kort Begrip met die aanhaling van Matteus 18: 15-17. (As jou broer teen jou sondig gaan bestraf hom tussen jou en hom alleen. As hy na jou luister, dan het jy jou broer gewin; maar as hy nie luister nie, neem nog een of twee met jou saam, sodat in die mond van twee of drie getuies elke woord kan vasstaan. En as hy na hulle nie luister nie, se dit vir die gemeente; en as hy na die gemeente ook nie luister nie, laat hom vir jou wees soos die heiden en die tollenaar.) Daar kan hoogstens gespekuleer word oor die teologiese gevolge wat hierdie verkorting in die kerk gehad het, maar dit is minstens waarskynlik dat die wanopvattings oor en die lou houding ten opsigte van die tug wat so geil in die Hervormde Kerk groei, hierheen teruggevoer kan word. Dit sou natuurlik alles berus op 'n wanbegrip van die Matteus-perikoop - maar aangesien die saak van sensuur en uiteindelik die ban nie eksplisiet ter sprake kom nie, kán die mening ontstaan dat die kerklike tug bestaan uit baie praat met die oortreder en, as hy dan nie wil luister nie, om hom dan maar uiteindelik te laat staan en hom as ' $n$ heiden te behandel. Dit is 'n opvatting wat, om die minste daarvan te sê, nie onbekend in die kerk is nie.

\section{KLEMVERSKUIWINGS AS GEVOLG VAN DIE BEDOELING OF GERIGT- HEID}

Die Kategismus was bedoel as ' $n$ versoenende dokument om hervormdes van verskillende gesindtes te verenig. Daarom het die Kategismus nie juis 'n polemiese inslag nie. Dit is in dié verband veral interessant om daarop te wys dat antwoord 80, 
die enigste werklike polemiese antwoord, dié een wat na die Mis verwys as 'n vervloekte afgodery, nie deel van die oorspronklike Kategismus was, soos deur die kommissie opgestel nie. Dit is deur Frederick sélf bygevoeg en dit waarskynlik ook net omdat die konsilie van Trente nie skaam was om sy anathema's links en regs uit te deel nie.

Die Kort Begrip daarenteen, is openlik polemies. Dit spreek veral duidelik uit bepaalde vrae en antwoorde wat nie in die Kategismus voorkom nie. Vraag 17 vra byvoorbeeld: Kan die heiliges ons middelaars nie wees nie? Dit is 'n vraag wat kennelik gemik is teen die Roomse gebruik om bepaalde mense heilig te verklaar en dan aan hulle die status van middelaar toe te ken. Vrae 70 en 71 borduur voort op dieselfde tema. Vraag 70 vra: Tot wie moet ons hiervoor bid? Die bekende antwoord lui: Nie tot enige skepsel nie, maar alleen tot God. Vraag 71 vra: In wie se naam moet ons tot God bid? Alleen in die naam van Christus en nie in die naam van enige heilige nie. Beide hierdie vrae is gemik teen Roomse praktyke wat nie onbekend was of is nie.

Daar vind egter nie net afgrensing teen die Rooms-Katolieke kerk plaas nie, maar ook teen die Dopers. Dit is verstaanbaar, gesien die feit dat die Kort Begrip veral ook daarop gemik was om bekeerlinge vanuit die Doperdom na hulle eerste nagmaalsviering te begelei. 'n Voorbeeld in dié verband wat hier aangehaal kan word, is vraag en antwoord 28: 'Het $\mathrm{Hy}$ (dit is Christus) sy mensheid dan uit die hemel gebring? Nee, Hy het nie, maar het dit aangeneem uit die maagd Maria ....' Dit is gemik teen die Doperse opvatting, wat teruggevoer kan word na Menno Simons, dat Jesus nie uit Maria vlees geword het nie, maar in haar. Die gedagte hieragter is dat Jesus (soos Simons gesê het) nie halfpad God se saad en halfpad menslike saad is nie, maar 'n ongemengde Christus na liggaam, siel en gees (Polman s a: 244).

\section{KLEMVERSKUTWING AS GEVOLG VAN TEOLOGIESE VERANDERINGS}

Die Reformatoriese teologie het tydens die bykans vyftig jaar wat verloop het vanaf die verskyning van die Kategismus tot by die eerste verskyning van die Kort Regrip, nie onveranderd gebly nie. Inteendeel, dit het gedurende hierdie tydperk al meer en meer die slagoffer geword van die verskynsel wat die kerk regdeur sy geskiedenis teister - naamlik dat daar, ná 'n periode van kreatiwiteit, onmiddellik 'n periode van stagnasie en skolastiek volg waartydens die insigte van die pionier-teoloog of groep teoloë vasgevang word in formules (Evans, McGrath \& Galloway 1986: 151). Die tydperk ter sprake is veral gekenmerk deur 'n skolastieke tendens. Onder 'skolastiek' verstaan ons: 'a method of theological and philosophical speculation that seeks the rational penetration and systematisation of revealed truth on the basis of 
philosophical concepts' (Evans, McGrath \& Galloway 1986: 155). Dit is Philippus Melanchton wat die twyfelagtige eer verdien dat hy die wegbereider vir die hertoetrede van die skolastiek in die teologie was. Dit was hy wat daarop aangedring het dat die filosofie as die ancilla theologia beskou moet word. Dit was egter Theodorus Beza wat gebrandmerk moet staan as die man wat die Aristotelianisme in die Reformatoriese teologie ingedra het. Dit dien daarop gelet te word dat sy twee hoofwerke in die tydperk tussen die verskyning van die Kategismus en die van die Kort Begrip verskyn het. Die Tractationes theologicae verskyn naamlik in 1570 en die Icones in 1580. Hy kon dus geen invloed op die opstelling van die Kategismus uitgeoefen het nie, maar mens sou kon verwag dat dit wel die geval kón wees ten opsigte van die opstelling van die Kort Begrip.

Beza se teologie word daardeur gekenmerk dat hy die rede as sodanig en die Aristoteliaanse logika in die besonder, verhef tot ' $n$ status gelykstaande aan geloof binne die ruimte van die teologiese epistemologie. Hierdie rasionalistiese inslag van sy teologie is veral opvallend in sy uitverkiesingsleer. Die verskille met Calvyn in dié verband is ooglopend. Calvyn se versigtige uitspraak in dié verband is gegrond op die Skrif en geplaas in die konteks van sy argumentering oor die verlossing. Vir hom is dit maar een aspek van die leer van die genade en beslis nie 'n leidende beginsel in sy teologiese metode nie. By Beza sien die saak heeltemal anders daaruit. Sy uitsprake in dié verband is minder versigtig en is gebaseer op 'n analise van die konsep van oorsaaklikheid en geplaas binne die konteks van sy Godsleer. Hiermee vind daar ' $n$ fundamentele verandering in klemlegging plaas. Vir hom is die uitverkiesing die sentrale leerstuk wat die logiese basis vir alle ander leerstukke vorm. Elke leerstuk wat die logiese gevolgtrekking van die leer van die uitverkiesing is, moet aanvaar word - en die logika wat hy aanwend, is die van Aristoteles. Sodoende kom hy sonder om te blik of te bloos tereg by die leer van die supralapsarisme en die beperkte versoening - wat stel dat Christus net vir die uitverkorenes gesterf het.

'n Ondersoek van die Kort Begrip bring gou aan die lig dat hierdie oortuiging van Beza ook dáár 'n onderdak gevind het. 'n Vergelyking tussen vraag 40 van die Kort Begrip en vraag 54 van die Kategismus laat dit duidelik aan die lig tree. Wat glo u van die heilige algemene kerk? Die Kort Begrip antwoord: 'Dat die Seun van God, uit die hele menslike geslag die uitverkorenes tot die ewige lewe, deur sy Gees en Woord, vir Hom tot 'n gemeente byeenbring ....' Die Kategismus daarenteen formuleer soos volg: 'Dat die Seun van God uit die ganse menslike geslag vir Hom 'n gemeente wat tot die ewige lewe uitverkies is, deur sy Gees en Woord in die eenheid van die ware geloof ... vergader, beskerm en onderhou.' 
Die formulering klink bykans dieselfde, maar daar is 'n ingrypende verskil tussen die twee. Volgens die Kategismus het mens deel aan die verkiesing, omdat jy aan die gemeente behoort. Volgens die Kort Begrip behoort jy aan die gemeente, omdat jy uitverkies is. Hierdie eenvoudige verskil in formulering is manifestasie van 'n geweldige klemverskuiwing: Die insig van Calvyn, wat deur die opstellers van die Kategismus gebruik is, dat die uitverkiesing 'n uitverkiesing in Christus is, het plek gemaak vir die ontwerp van Beza.

Van Selms (1957: 44) het aangedui dat die gevolge hiervan bykans onoorsienbaar is. 'Die Kort Begrip bied 'n aanknopingspunt vir die idividualisme, vir die meganiese opvatting van die uitverkiesing, vir die sisteem van Maccovius en vorm 'n eerste aanloop vir Kuyper se aanvegbare leer van die veronderstelde wedergeboorte.'

'n Verdere voorbeeld van die skolastieke inslag van die Kort Begrip vind ons in vraag 26. Die vraag vra of die Godheid van die Seun in mensheid verander is en die antwoord lui: 'Nee, want die Godheid is onveranderlik.' Hierdie antwoord word gestaaf met 'n verwysing na Maleagi 3: 6, wat in die 1933 vertaling lui: 'Want $E k$, die Here, het nie verander nie; daarom is julle, kinders van Jakob, nie verteer nie.' Dit wil dus, so met die eerste oogopslag, voorkom asof die uitspraak van die Kort Begrip Bybels legitiem moet wees. Dit is egter net skyn en berus op die voorkoms van gelykluidende woorde. Wat die profete-uitspraak se, is dat God getrou is, dat Hy vashou aan sy heilsplan ten aansien van sy volk en dat dit beteken dat sy wil onveranderlik op die verlossing van sy volk gerig bly. Dit kan dus onmoontlik nie gebruik word om as bewys te dien vir die stelling dat God nie 'n mens kan word nie. Hierdie laasgenoemde stelling is hoegenaamd nie 'n Bybelse stelling nie, maar is afkomstig uit die Aristotelianisme en is aanduidend van 'n strak, filosofiese Godsbeeld.

Die gebruik van die aanhaling is bedenklik, maar die argument daaragter nog bedenkliker. Die Bybelse getuienis aangaande die morele onveranderlikheid van God word omgebuig tot 'n stelling aangaande sy fisiese onveranderlikheid skolastiek in die verfyndste vorm van die woord.

Die invloed hiervan loop waarskynlik baie breêr in die kerklike denke as wat mens graag sou wou vermoed. Dit het ongetwyfeld aanleiding gegee tot die vestiging van die filosofiese Godsbeeld in die denkwêreld van die deursnee lidmaat wat die vormende invloed van die Kort Begrip ondergaan het. Dit het gebruiklik geword om in terme van onveranderlikheid van God te praat en aan Hom te dink om dan, op voortgaande skolastieke wyse hieruit op deduktiewe wyse verdere afleidings aangaande sy eienskappe en sy verhouding met die mense te maak. 
Dit is opvallend dat die Kategismus nie 'n ooreenstemmende vraag en antwoord bevat nie en ook nie op so 'n eg filosofiese wyse oor God praat nie. Die Kategismus se spreke oor God is Christosentries van aard en die woordjie 'God' word nooit gebruik sonder dat dit om God in Jesus Christus gaan nie. Dieselfde kan natuurlik nie ten opsigte van die Nederlandse Geloofsbelydenis gesê word nie. Daar is, selfs op die veel vroeër tydstip van sy ontstaan, ook al reeds sterk skolastieke tendense aan die werk - en veral ten opsigte van die belydenis oor God. Wanneer Artikel 1 byvoorbeeld bely: Ons glo almal met die hart en bely met die mond dat daar ' $n$ enige en enkelvoudige geestelike wese is wat ons God noem: Ewig, onbegryplik, onsienlik, onveranderlik, oneindig, almagtig ... is dit filosofiese kategorieë wat ter sprake kom en nie Bybelse nie.

'n Tweede en laaste voorbeeld om die skolastieke inslag van die Kort Begrip bo alle twyfel te stel is vrae 33 en 34 . Vraag 33 vra in watter natuur Jesus Christus gely het, waarop geantwoord word dat dit slegs in sy menslike natuur was en vraag 34 vra na die rol van sy Godheid in sy lyding. Die antwoord: 'Sy Godheid het deur sy krag die aangenome mensheid so gesterk, dat dit die las van die toorn van God teen die sonde kon dra en ons daarvan verlos.'

Hierdie vrae, wat $66 \mathrm{k}$ nie in die Kategismus voorkom nie, ruk die persoon van Jesus uitmekaar op 'n wyse wat onverenigbaar is met die Bybelse getuienis (Van Selms, 1957: 48). Die kerk het uiteindelik, in 'n poging om die persoonsgeheimenis van Jesus Christus geformuleer te kry, sy toevlug tot die twee natureleer geneem. Dit het egter nooit beteken dat Jesus Christus as 'n soort dubbelslagtige wese gesien is nie. Die twee nature was nooit anders ter sprake as binne die enigheid van sy Persoon nie. Daarom het die kerk die leer van die an- en enhupostasie ontwikkel in 'n poging om die raaisel van die verhouding tussen die nature op een of ander manier te formuleer. Van 'n radikale skeiding tussen die nature - in die sin waar daar in die Kort Begrip daarvan gepraat word, was daar nooit sprake nie. Dit is ook 'n stukkie erfenis uit die Aristotelianisme. Vir hom was dit ondenkbaar dat God kan ly en daarom kan die Godheid as sodanig ook nie ly nie.

Die Bybel het daarteenoor ' $n$ totaal ander insig in wat God is en praat by geleentheid onbevange oor die smart van God. Vergelyk in die verband onder andere Genesis 6: 6: ' '.. die Here (was) bedroef daaroor dat Hy die mens op die aarde gemaak het. Dit het Hom diep gegrief.' Dit is minstens 'n aanduiding daarvan dat die Bybelse denke oor God Hom nie as 'n apatiese monade, ongeraak en ongeroer deur sy skepping, voorstel nie - maar as 'n Persoon - in lewende gemeenskap met sy volk.

Dit is 'n ope vraag in hoeverre formulerings, soos die in antwoorde 33 en 34, daartoe bygedra het om die bestaan van die filosofiese Godsbeeld in die kerk te 
bestendig. Dit behoort duidelik te wees dat die bydrae nie gering kon gewees het nie.

\section{SLOTSOM}

Uit bostaande blyk dit dat die Kort Begrip in vele opsigte 'n verwording van die Reformatoriese teologie verteenwoordig. Waaroor hier hoofsaaklik bespiegel is, naamlik die gevolge van die geslagtelange gebruik van hierdie boekje as kategeseboek (en gevolglik bykans enigste kontak met die leer van die kerk vir die deursnee lidmaat) vir die teologie en kerklike lewe van die Nederduitsch Hervormde Kerk sal by wyse van 'n afsonderlike, uitgebreide ondersoek duidelikheid verkry moet word. Dit sal 'n geweldige taak wees, maar dit mag van meer as bloot net historiese betekenis wees.

\section{Literatuurverwysings}

BAKHUIZEN VAN DEN BRINK, JN 1976. De Nederlandse Belijdenis geschriften. Amsterdam: Ton Bolland.

BARGER, HH 1914. De Heidelbergsche Catechismus als catechetisch leerboek. Utrecht: Hemink en Zoon.

BARTH, K 1948. Die christliche lehre nach dem Heidelberger Katechismus. Zürich: Evangelischer Verlag.

CALVIN, J 1978. Christliche Unterweisung, der Genfer Katechismus von 1537. Gütersloh: Gütersloher Verlagshaus.

COENEN, L (Hrsg) 1963. Handbuch zum Heidelbenger Katechismus. Neukirchen: Neukircherner Verlag.

EVANS, GR et al 1986. The history of Christian theology, Vol 1: The science of theology. Eerdmans: Grand Rapids.

GOOSEN, MA 1890. De Heidelbergsche Catechismus: Bijdrage tot de kennis van zijne wordingsgeschiedenis en van het gereformeerd protestantisme. Leiden: Brill.

HAITJEMA, Th D 1962. De Heidelbergse Catechismus. Wageningen: Veenmon en Zonen.

HARTVELT, GP et al 1966. Alles in Hem. Aalten: De Graafschap.

KERKBOEK VAN DIE NEDERDUITSCH HERVORMDE KERK VAN AFRIKA 1958. Kaapstad: NG Kerkuitgewers.

LUTHER, M. Kleiner Katechismus mit Erklärung. Hanover: Schlütersche Buchdruckerei.

MOLTMANN, J 1977. The church in the power of the Spirit. London: SCM. 
Die Heidelbergac Katcgismus en die Kort Begrip

POLMAN, ADR s a. Onze Nederlandsche Geloofsbelijdenis, Deel II. T Wever Franeker.

VAN SELMS, A 1957. Die Kort Begrip in die Katkesasie, in Die Almanak van die Nederduitsch Hervormde Kerk van Afrika, Jaargang 45. 